\title{
Sleep quality and common mental disorder in the hospital Nursing team*
}

\author{
Jolana Cristina Cavalheiri ${ }^{1}$ \\ (iD) https://orcid.org/0000-0002-9549-8985 \\ Claudicéia Risso Pascotto \\ (iD) https://orcid.org/0000-0003-1265-2316 \\ Nelsi Salete Tonini ${ }^{3}$ \\ (1D) https://orcid.org/0000-0003-4704-7634 \\ Ana Paula Vieira ${ }^{2}$ \\ (1D) https://orcid.org/0000-0003-2743-4813 \\ Lirane Elize Defante Ferreto ${ }^{2}$ \\ (ID) https://orcid.org/0000-0002-0757-3659 \\ Franciele Ani Caovilla Follador ${ }^{2}$ \\ (DD) https://orcid.org/0000-0002-9210-1540
}

Objective: to determine the prevalence of sleep quality and common mental disorder in Nursing professionals and factors associated with sleep change. Method: a cross-sectional, analytical and quantitative study developed with 196 Nursing professionals of a public hospital and a mixed one. Data was collected by means of an instrument of sociodemographic characterization, by the Self-Report Questionnaire 20 and Pittsburgh Sleep Quality Index and were analyzed by descriptive and inferential statistics to identify possible factors associated with sleep changes. Results: sleep changes were identified among the Nursing professionals with a frequency of $76.5 \%$ (70.4-82.1). Sleep quality was classified as poor in $41.8 \%$ (41.8-55.6) and sleep disorder in 27.6\%. (21.4-34.2). The prevalence of common mental disorder was identified in $36.7 \%$ (30.1-43.9). The main factor for poor sleep quality was the presence of common mental disorder (Odds Ratio: 5.15; $\mathrm{p}<0.001)$. Conclusion: sleep changes were prevalent and the characteristics of the work environment and the presence of mental disorder showed relevance in the changes.

Descriptors: Nurse Practitioners; Occupational Health Nursing; Occupational Health; Sleep; Mental Disorders; Hospitals.

\section{How to cite this article}

Cavalheiri JC, Pascotto CR, Tonini NS, Vieira AP, Ferreto LED, Follador FAC. Sleep quality and common mental disorder in the hospital Nursing team. Rev. Latino-Am. Enfermagem. 2021;29:e3444. [Access $\frac{1}{1} \frac{1}{1}$ ]; Available in: DOI: http://dx.doi.org/10.1590/1518-8345.4280.3444 


\section{Introduction}

Work is an important factor for human life and society development as it allows purchasing goods, as well as it influences the physical and mental health of the individual(1-2). However, with globalization, the incorporation of technologies, production demand, qualification and the new ways of management, important changes were observed in the work dynamics of several sectors of society ${ }^{(3)}$.

These transformations impacted workers' health, as many national and international studies have been demonstrating that the work activity has an effect on professional illnesses ${ }^{(4-7)}$. Situations such as work fragmentation, excessive workload, complexity of the service, accumulation of functions to reach the goals, as well as low wages and the terrible working conditions are organizational features that can negatively intervene in the professional's health and quality of life ${ }^{(8)}$. In the hospital environment, these situations add up to the contact with at risk patients and to the need to make important decisions ${ }^{(9)}$, which turn this place into one of the most complex health services.

Thus, the largest workforce in the hospital environment is the Nursing team, which remains with the patient 24 hours a day and offers continuous care. In this profession, the work process is developed collectively and is fragmented into three categories: the Nursing assistant and technician, who perform hygiene and comfort tasks, and less complex procedures and the nurse, who acts as team supervisor and service manager ${ }^{(1)}$.

These particularities of each category, along with the organization of the hospital's work process, are related to the development of work-associated health changes ${ }^{(3)}$. Among them, the complaints on poor sleep quality are common, especially in the individuals that work in the night shift( ${ }^{(4)}$.

It is known that sleep deprivation favors daytime sleepiness, diminishes the alert state, increases the chance of injuries and work accidents, contributes to cognitive overload, reduces performance in the activities and analytical reasoning, leads to cognitive failure and is associated with two times more errors by the Nursing team ${ }^{(9-10)}$, being considered one of the main threats to patient safety in hospital units(4).

Sleep impairment and wearing work show relevance in the mental and physical health of the professionals, with worsening in quality of life, irritability, chronic fatigue, anxiety, depression, tiredness and development of mental disorders ${ }^{(5,11-12)}$. Among them, there is minor or common mental disorder (CMD; transtorno mental comum-TMC-in Portuguese language), a less severe group of psychiatric disorders, which involves loss of concentration, forgetfulness, somatic complaints, and fatigue $^{(13)}$, being associated with the characteristics of the work environment ${ }^{(6,9,14)}$.

It is to be pointed out that, in a study developed in Iran with nurses in hospital units, the prevalence of professionals with poor sleep was obtained ${ }^{(10)}$, as well as a research study conducted in a general hospital in the state of Bahia (Brazil), in which the professionals presented sleepiness and insomnia as common complaints( ${ }^{(6)}$. In addition, in a study developed in the state of Paraná (Brazil) it was found that the professionals of the night shift, who are dissatisfied with sleep, presented increased chances of emotional exhaustion(7).

In face of this issue which involves the Nursing team, it is important to know the changes in sleep and mood experienced by the professionals and their relationship with the work environment, in order to propose changes in the hospital that minimize the negative effects of work on health and improve the quality of life of the professionals. Thus, the guiding questions of the study were as follows: What is the prevalence of mental and sleep changes in Nursing professionals in the hospital environment? And what factors are associated with poor sleep quality?

From this assumption, this research aimed to determine the prevalence of sleep quality and common mental disorder in Nursing professionals and factors associated with sleep change.

\section{Method}

This is a cross-sectional, analytical, and quantitative study developed with assistance Nursing professionals from a public hospital, and from another mixed one, in Francisco Beltrão, Paraná (PR), Brazil.

The Human Development Index for the aforementioned municipality is $\mathbf{0 . 7 7 4}$, and this city is a health care hub for the population of Southeast of the State of Paraná, hosting the $8^{\text {th }}$ Health Region. The health sector in the municipality manages the operation of care through a network composed of basic, specialized and tertiary units. The basic network covers $75.07 \%$ of the population. As for the tertiary units, they correspond to four hospitals, one managed by the State, one private and two with mixed management (public/private), which have 476 Nursing professionals altogether.

Two tertiary units were selected for the study. The first, a mixed hospital unit, with private service, under agreements with the Unified Health System (UHS; SUS is the name given in Brazil to the public health system), with 72 beds. Care is directed to the following specialties: general surgery, medical clinic, obstetrics, pediatrics, and it also has an Adult Intense Care Unit (10 beds). The second is a State-managed, tertiary unit, which serves only the UHS. It can serve medium- and high-complexity 
cases, with 108 beds, offering services in the following specialties: trauma orthopedics, surgical and medical clinic, obstetrics, pediatrics, and psychiatry. It features an Adult Intensive Unit Care (10 beds), a Neonatal Intensive Care Unit (10 beds), and a Conventional Neonatal Intermediate Care Unit ( 5 beds).

These places were chosen for the study due to their very similar characteristics in serving the population, but with differences in hospital management. All the Nursing professionals who work in both hospital units were invited to participate in the research, totaling 266 workers. Of this total, 196 Nursing professionals participated in the study: 44 nurses (22.4\%) and 152 nursing technicians (77.6\%) (Figure 1 ). The participants performed tasks in both institutions and were included in the study only once.

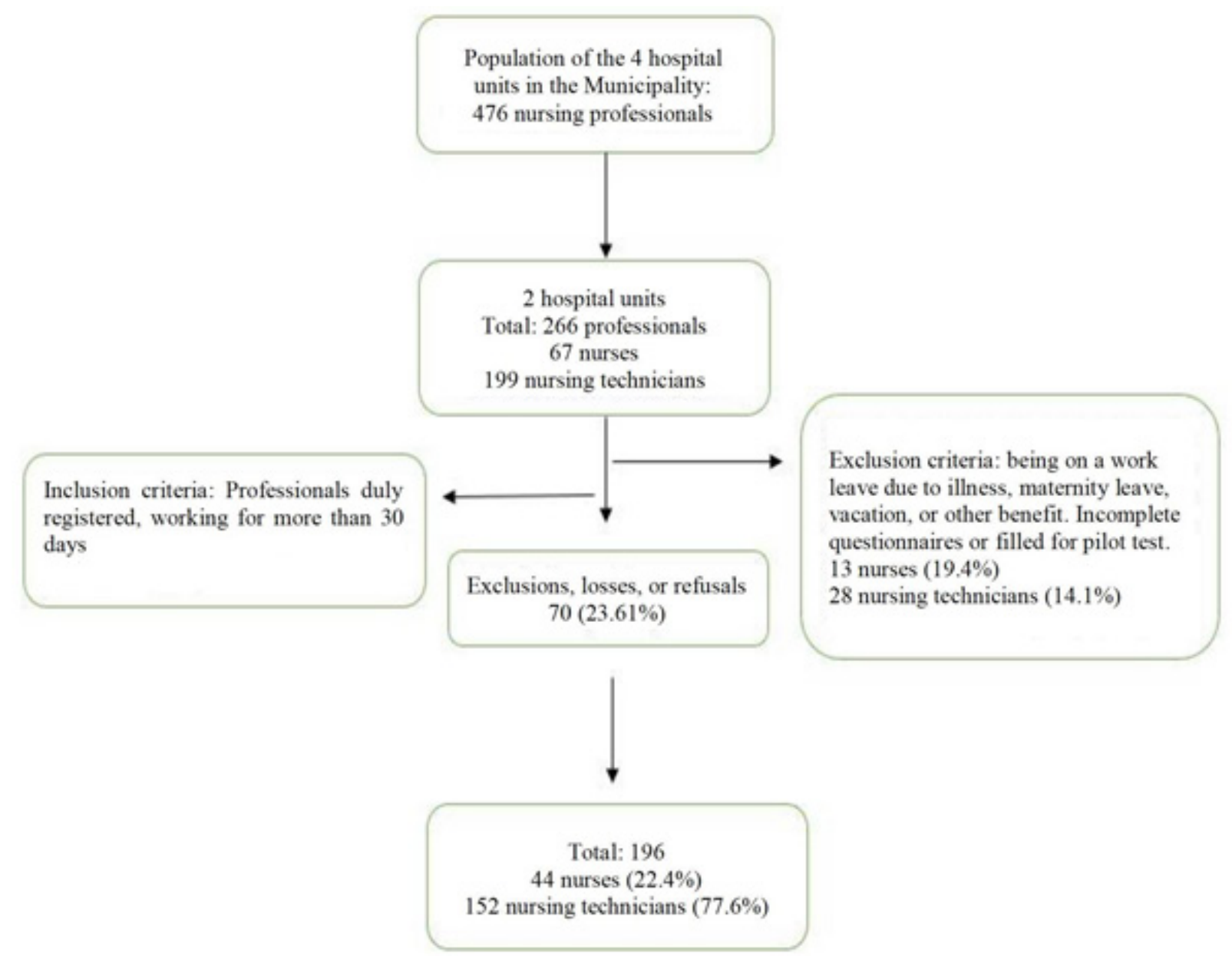

Figure 1 - Flowchart of the sample selection. Francisco Beltrão, PR, Brazil, 2018

The data were collected from February to August 2018 by filling in self-response questionnaires, in which the professionals, first of all, received guidelines for their completion during the shift break periods or at the beginning and end of each shift, with any possible doubt being clarified. Aiming at greater adherence by the professionals and to avoid interruptions of their assistance activities, the questionnaires were handed in with a 10day return deadline.

With an organizational method of data collection, it was chosen to divide the instruments into blocks, the first being a questionnaire composed of sixteen closed questions that contemplated the sociodemographic and occupation data elaborated by the researchers, according to the national and international literature. The studied variables were age, gender, schooling, marital status, self-referred skin color, family income, professional category, work period, academic training, time working in the profession and at the institution, if they had more than one job, and weekly working hours. A pilot test was carried out to clarify possible doubts, making the instrument available to 5 Nursing professionals of each institution, from various units. There was no need to adapt the survey questionnaire and the pilot test respondents were excluded from the final sample.

As for the second block, it aimed to assess mental health, in which the SRQ-20 (Self-Report Questionnaire) Mental Disorders Assessment Questionnaire was used, validated in Brazil in 1986, which is composed of 20 questions divided into characteristic symptoms of 
depressive-anxious and somatic mood, decreased vital energy and depressive thoughts. The alternatives were dichotomized into affirmative and negative. This has the objective of tracking non-psychotic disorders ${ }^{(15)}$. The instrument score varies from 0 to 20 points, with values $\geq 7$ indicating the possibility of common mental disorder (CMD).

Finally, the third assessment block consisted of the verification of sleep quality, in which the Pittsburgh Sleep Quality Index (PSQI) was used, validated in Brazil in 2008. This instrument assesses the perception of sleep in the last 30 days and is composed of 19 self-applied questions. These questions are grouped into seven components: subjective sleep quality, sleep latency, sleep duration, usual sleep effectiveness, sleep disorders, use of medications to sleep and daytime dysfunction. The global score varies from 0 to 21 , with values under 4 indicating good quality; from 5 to 9 points, poor quality and over 10 points, presence of sleep disorders ${ }^{(16)}$.

The data were inserted into a Microsoft Excel for Windows/7 (Microsoft Office 2007) spreadsheet and later explored in the IBM SPSS Statistics statistical package, version 21 and in the Minitab Statistical Software, version 16. The absolute $(n)$ and relative $(\%)$ frequencies were used to describe the characteristics of the sample.

Initially, the Pittsburgh Sleep Quality Index was categorized into absence (a score below 4, considered good sleep quality) and presence (higher than 5, considered as poor sleep quality and sleep disorder) of sleep changes. Immediately after that, for a comparison between presence or absence of sleep changes and the categorical variables, the chi-square test with continuity correlation was performed. The variables that presented $p<0.25$ in this analysis were inserted in the binary logistic regression model to identify possible factors associated with sleep changes, with values that presented $p<0.05$ being considered statically significant. The model correctly classified $65.8 \%$ of the cases and explained $10.1 \%$ of the variance (Cox and Snell $\mathrm{R}^{2}$ ). The assumption of normal distribution was tested by the KolmogorovSmirnov test. Considering that the distribution did not meet the assumptions of the parametric statistics, the non-parametric Kruskal-Wallis test was used to verify the relationship between the independent variables and the scores of the sleep instruments, only the variables with statistical significance $(p<0.05)$ being presented (Table 3 ).

Thus, this study followed the ethical recommendations in research with human beings and, initially, authorization was requested from the hospital institutions for the research to be carried out. Subsequently, it was submitted to the Ethics and Research Committee of the State University of Western Paraná and approved on December $4^{\text {th }}, 2017$, under opinion No. 2.415.008.

\section{Results}

With this research it was possible to analyze that, among the 196 Nursing professionals, there was a predominance of nursing technicians (78.7\%), females ( $88 \%)$, aged over 36 years old (58.7\%) and receiving more than 3 minimum wages (71.3\%).

Sleep changes were identified among the Nursing professionals with a frequency of $76.5 \%(n=150)$ (95\% CI: 70.4-82.1). Sleep quality was classified as poor in $41.8 \%(n=96)(95 \%$ CI: 41.8-55.6), followed by sleep disorder in $27.6 \%(n=54)(95 \%$ CI: $21.4-$ 34.2). A prevalence of common mental disorder was identified in $36.7 \%(n=72)$ (95\% CI: 30.1-43.9). The sociodemographic, occupational and CMD characteristics are in the table presented in continuity (Table 1 ).

Table 1 - Sociodemographic and occupational characterization, common mental disorder and sleep changes among Nursing professionals $(n=196)$. Francisco Beltrão, PR, Brazil, 2018

\begin{tabular}{|c|c|c|c|c|c|}
\hline \multirow{3}{*}{ Variables } & \multicolumn{4}{|c|}{ Sleep Changes } & \multirow{3}{*}{$\mathrm{p}$-value } \\
\hline & \multicolumn{2}{|c|}{ Presence } & \multicolumn{2}{|c|}{ Absence } & \\
\hline & $(\mathrm{N}=150)$ & $(\%)$ & $(\mathrm{N}=46)$ & $(\%)$ & \\
\hline Professional category & & & & & 0.635 \\
\hline Nurses & 32 & 21.3 & 12 & 26.1 & \\
\hline Nursing Technicians & 118 & 78.7 & 34 & 73.9 & \\
\hline Gender & & & & & 1.000 \\
\hline Female & 132 & 88 & 41 & 89.1 & \\
\hline Male & 18 & 12 & 05 & 20.9 & \\
\hline Age group (years old) & & & & & 0.091 \\
\hline 18 to 35 & 62 & 41.3 & 12 & 26.1 & \\
\hline
\end{tabular}




\begin{tabular}{|c|c|c|c|c|c|}
\hline \multirow{3}{*}{ Variables } & \multicolumn{4}{|c|}{ Sleep Changes } & \multirow{3}{*}{$\mathrm{p}$-value } \\
\hline & \multicolumn{2}{|c|}{ Presence } & \multicolumn{2}{|c|}{ Absence } & \\
\hline & $(N=150)$ & $(\%)$ & $(\mathrm{N}=46)$ & $(\%)$ & \\
\hline Over 36 & 88 & 58.7 & 34 & 73.9 & \\
\hline Skin color & & & & & 0.545 \\
\hline White & 119 & 79.3 & 39 & 84.8 & \\
\hline Brown/black & 31 & 20.7 & 07 & 15.2 & \\
\hline Schooling & & & & & 0.702 \\
\hline Technical education & 91 & 60.7 & 30 & 65.2 & \\
\hline Higher education or above & 59 & 39.3 & 16 & 34.8 & \\
\hline Marital status & & & & & 0.083 \\
\hline Single & 59 & 39.3 & 11 & 23.9 & \\
\hline Married/Stable union & 91 & 60.7 & 35 & 76.1 & \\
\hline Family income (minimum wages*) & & & & & 0.878 \\
\hline Less than 3 & 43 & 28.7 & 12 & 26.1 & \\
\hline More than 3 & 107 & 71.3 & 34 & 73.9 & \\
\hline Time in the profession (years) & & & & & 0.480 \\
\hline Up to 10 & 86 & 57.3 & 23 & 50 & \\
\hline Over 10 & 64 & 42.7 & 23 & 50 & \\
\hline Hospital Unit & & & & & 1.000 \\
\hline Public & 100 & 66.7 & 31 & 67.4 & \\
\hline Private/Public & 50 & 33.3 & 15 & 32.6 & \\
\hline Time working in the institution (years) & & & & & 0.783 \\
\hline 6 or less & 50 & 33.3 & 17 & 37 & \\
\hline Over 6 & 100 & 66.7 & 29 & 63 & \\
\hline Number of jobs & & & & & 0.562 \\
\hline Only 1 & 116 & 77.3 & 33 & 71.7 & \\
\hline 2 or more & 34 & 22.7 & 13 & 28.3 & \\
\hline Number of weekly working hours & & & & & 1.000 \\
\hline Up to 40 & 87 & 58 & 25 & 54.3 & \\
\hline 41 or more & 63 & 42 & 21 & 45.7 & \\
\hline Employment contract & & & & & 1.000 \\
\hline Statutory & 101 & 67.3 & 31 & 67.4 & \\
\hline Service provision & 49 & 32.7 & 15 & 32.6 & \\
\hline Working shift & & & & & 0.357 \\
\hline Day & 95 & 63.3 & 25 & 54.3 & \\
\hline Night & 55 & 36.7 & 21 & 45.7 & \\
\hline Have worked in the night shift & & & & & 0.430 \\
\hline Yes & 117 & 78.0 & 39 & 84.8 & \\
\hline Never & 33 & 22.0 & 07 & 15.2 & \\
\hline Common Mental Disorder & & & & & $<0.001$ \\
\hline No & 84 & 56 & 40 & 87 & \\
\hline Yes & 66 & 44 & 06 & 13 & \\
\hline
\end{tabular}

*Brazilian minimum wage in 2018: $\mathrm{R} \$ 954.00$ (nine hundred and fifty-four reais) 
Regarding the variables in Table 1 , it is observed that age group, marital status and common mental disorder presented $\mathrm{p}<0.25$ and were inserted in the logistic regression model to identify factors associated with sleep changes (Table 2). However, only one of the three variables presented statistical significance: common mental disorder. Thus, the Nursing professionals who were classified with CMD presented a 5 times higher probability of sleep changes ( $p$-value $<0.001$ ).

Table 2 - Factors associated with the presence of sleep changes in Nursing professionals in Francisco Beltrão, PR, 2018

\begin{tabular}{|c|c|c|c|c|}
\hline Variable & $\operatorname{grOR}^{*}\left(95 \% \mathrm{Cl}^{+}\right)$ & $p$-value & $\operatorname{adOR}^{\ddagger}(95 \% \mathrm{Cl})$ & $p$-value \\
\hline \multicolumn{5}{|l|}{ Age group (years old) } \\
\hline 18 to 35 & 1 & & & \\
\hline Over 35 & $1.99(0.95-4.15)$ & 0.091 & ----- & \\
\hline \multicolumn{5}{|l|}{ Marital Status } \\
\hline No partner & 1 & & & \\
\hline Has a partner & $2.06(0.97-4.37)$ & 0.083 & ---- & \\
\hline \multicolumn{5}{|l|}{ Common mental disorder } \\
\hline Absence & 1 & & 1 & \\
\hline Presence & $5.23(2.09-13.1)$ & $<0.001$ & $5.15(2.04-12.90)$ & $<0.001$ \\
\hline
\end{tabular}

${ }^{*}$ grOR = Odds Ratio $;{ }^{+} \mathrm{CI}=95 \%$ Confidence Interval; ${ }^{\ddagger}$ adOR = Odds Ratio (adjusted measures)

The mean time to fall asleep was 31.9 minutes, with a mean of 6.5 sleep hours. Regarding the perception of sleep quality, $32.1 \%$ referred having good sleep; $31.1 \%$, poor; $18.9 \%$, very good and $17.9 \%$, very poor. The consumption of sleeping medications was mentioned by $33.2 \%$ of the participants.

When the sociodemographic and occupational characteristics were assessed with the domains of the sleep quality instrument, it was observed that all the scores presented statistical significance with some variable, in which the public hospital obtained higher mean scores in subjective sleep quality, sleep disorder, use of sleep medications and daytime dysfunction. It was also verified that a working time of more than 6 years at the institution presented statistical significance in subjective sleep quality, sleep latency, sleep disorders and use of sleep medications, according to Table 3.

Table 3 - Mean scores of the sociodemographic and occupational variables with the domains of the Pittsburgh Sleep Quality Index of Nursing professionals $(n=196)$. Francisco Beltrão, PR, Brazil, 2018

\begin{tabular}{|c|c|c|c|c|c|c|c|c|c|c|c|c|c|c|c|}
\hline \multirow[b]{2}{*}{ Variable } & \multirow[b]{2}{*}{ Description } & \multicolumn{2}{|c|}{$\begin{array}{l}\text { Subjective } \\
\text { quality }\end{array}$} & \multicolumn{2}{|c|}{ Sleep latency } & \multicolumn{2}{|c|}{$\begin{array}{c}\text { Sleep } \\
\text { duration }\end{array}$} & \multicolumn{2}{|c|}{$\begin{array}{c}\text { Usual } \\
\text { effectiveness }\end{array}$} & \multicolumn{2}{|c|}{$\begin{array}{c}\text { Sleep } \\
\text { Disorders }\end{array}$} & \multicolumn{2}{|c|}{$\begin{array}{c}\text { Medication } \\
\text { use }\end{array}$} & \multicolumn{2}{|c|}{$\begin{array}{c}\text { Daytime } \\
\text { dysfunction }\end{array}$} \\
\hline & & $\begin{array}{l}\text { Mean } \\
\text { Score }\end{array}$ & $\mathrm{p}$-value & $\begin{array}{l}\text { Mean } \\
\text { Score }\end{array}$ & $p$-value & $\begin{array}{l}\text { Mean } \\
\text { Score }\end{array}$ & $\mathrm{p}$-value & $\begin{array}{l}\text { Mean } \\
\text { Score }\end{array}$ & $\mathrm{p}$-value & $\begin{array}{l}\text { Mean } \\
\text { Score }\end{array}$ & $p$-value & $\begin{array}{l}\text { Mean } \\
\text { Score }\end{array}$ & $\mathrm{p}$-value & $\begin{array}{l}\text { Mean } \\
\text { Score }\end{array}$ & $\mathrm{p}$-value \\
\hline Hospital & $\begin{array}{l}\text { Public } \\
\text { Private }\end{array}$ & $\begin{array}{l}103.9 \\
87.5\end{array}$ & 0.030 & $\begin{array}{l}103.3 \\
88.8\end{array}$ & 0.080 & $\begin{array}{l}100.1 \\
95.3\end{array}$ & 0.550 & $\begin{array}{c}96.3 \\
102.9\end{array}$ & 0.370 & $\begin{array}{l}105.4 \\
84.6\end{array}$ & $<0.001$ & $\begin{array}{l}103.5 \\
88.5\end{array}$ & 0.030 & $\begin{array}{l}104.9 \\
85.5\end{array}$ & 0.010 \\
\hline Gender & $\begin{array}{c}\text { Female } \\
\text { Male }\end{array}$ & $\begin{array}{l}98.9 \\
95.8\end{array}$ & 0.790 & $\begin{array}{l}98.9 \\
95.2\end{array}$ & 0.750 & $\begin{array}{c}97.4 \\
106.5\end{array}$ & 0.450 & $\begin{array}{l}98.8 \\
96.2\end{array}$ & 0.810 & $\begin{array}{l}99.9 \\
88.1\end{array}$ & 0.290 & $\begin{array}{l}100.9 \\
80.6\end{array}$ & 0.040 & $\begin{array}{l}98.9 \\
95.8\end{array}$ & 0.800 \\
\hline Skin color & $\begin{array}{l}\text { White } \\
\text { Black }\end{array}$ & $\begin{array}{c}96.9 \\
105.2\end{array}$ & 0.370 & $\begin{array}{c}97.4 \\
103.3\end{array}$ & 0.540 & $\begin{array}{l}98.6 \\
98.1\end{array}$ & 0.950 & $\begin{array}{l}102.7 \\
81.2\end{array}$ & 0.010 & $\begin{array}{c}97.3 \\
103.4\end{array}$ & 0.510 & $\begin{array}{c}96.7 \\
106.1\end{array}$ & 0.270 & $\begin{array}{l}99.6 \\
93.7\end{array}$ & 0.540 \\
\hline $\begin{array}{l}\text { Number of } \\
\text { jobs }\end{array}$ & $\begin{array}{c}\text { Only } 1 \\
2 \text { or more }\end{array}$ & $\begin{array}{l}100.5 \\
92.2\end{array}$ & 0.340 & $\begin{array}{l}104.3 \\
80.1\end{array}$ & $<0.001$ & $\begin{array}{l}100.6 \\
91.7\end{array}$ & 0.320 & $\begin{array}{l}94.6 \\
110.9\end{array}$ & 0.040 & $\begin{array}{l}99.7 \\
94.6\end{array}$ & 0.540 & $\begin{array}{l}102.3 \\
86.3\end{array}$ & 0.040 & $\begin{array}{l}96.8 \\
103.9\end{array}$ & 0.430 \\
\hline $\begin{array}{l}\text { Working } \\
\text { Hours }\end{array}$ & $\begin{array}{c}\text { Up to } 40 \\
\text { More than } 40\end{array}$ & $\begin{array}{l}98.7 \\
97.9\end{array}$ & 0.890 & $\begin{array}{l}103.4 \\
91.9\end{array}$ & 0.140 & $\begin{array}{c}98 \\
99.2\end{array}$ & 0.880 & $\begin{array}{l}92.2 \\
107\end{array}$ & 0.030 & $\begin{array}{c}98.9 \\
98\end{array}$ & 0.890 & $\begin{array}{r}103 \\
92.5\end{array}$ & 0.1270 & $\begin{array}{l}94.8 \\
103.4\end{array}$ & 0.270 \\
\hline Work Shift & $\begin{array}{l}\text { Day } \\
\text { Night }\end{array}$ & $\begin{array}{l}97.8 \\
99.7\end{array}$ & 0.790 & $\begin{array}{l}102.5 \\
92.3\end{array}$ & 0.200 & $\begin{array}{r}108 \\
83.5\end{array}$ & $<0.001$ & $\begin{array}{l}100.5 \\
95.4\end{array}$ & 0.480 & $\begin{array}{c}97.3 \\
100.4\end{array}$ & 0.710 & $\begin{array}{l}101.4 \\
93.9\end{array}$ & 0.280 & $\begin{array}{l}93.4 \\
106.6\end{array}$ & 0.090 \\
\hline $\begin{array}{l}\text { Time } \\
\text { working } \\
\text { (years) }\end{array}$ & $\begin{array}{l}\text { Up to } 6 \\
\text { Over } 6\end{array}$ & $\begin{array}{c}82.7 \\
106.7\end{array}$ & $<0.001$ & $\begin{array}{c}85.6 \\
105.2\end{array}$ & 0.010 & $\begin{array}{l}99.3 \\
98.1\end{array}$ & 0.870 & $\begin{array}{l}104.8 \\
95.2\end{array}$ & 0.190 & $\begin{array}{c}81.7 \\
107.2\end{array}$ & $<0.001$ & $\begin{array}{r}84 \\
106\end{array}$ & $<0.001$ & $\begin{array}{c}90.5 \\
102.7\end{array}$ & 0.130 \\
\hline
\end{tabular}




\section{Discussion}

A number of studies have demonstrated that the work dynamics of the Nursing team generates high absenteeism rates, with implications on the physical and mental health of these professionals, who are responsible for the provision of comprehensive care and management aspects in the hospital units. In this research, it was sought to investigate two aspects that interfere with the occupational quality of the Nursing professionals and that, in general, contribute to their distancing from the service. Such aspects are the presence of minor mental disorders represented by CMD and sleep quality ${ }^{(17)}$.

In this study, it was verified that the characteristics of the Nursing professionals are similar to those of other research studies in Brazilian hospital units ${ }^{(1,7,9,18)}$. These data were also observed in a study developed in a university hospital in the state of Minas Gerais, where $87.9 \%$ of the professionals were women, with a mean age of 40.2 years old ${ }^{(19)}$. Another study conducted with Nursing technicians in Montes Claros, Minas Gerais, indicated that $58.6 \%$ were female, with a mean age of 38.5 years old(20). A study developed with 540 nurses in 6 hospital institutions in Iran found that $66.3 \%$ were women with a mean age of 32 years old ${ }^{(11)}$, data similar to those in this research.

In relation to income, most of the professionals reported earning from three to five minimum wages, having only one job and working up to 40 hours during the week, which is similar to a research study carried out in the North of Paraná (Brazil), in which professionals had only one job (56.7\%) and earned from one to two minimum wages ${ }^{(7)}$. Likewise, another study developed in China, with nurses working in different hospital units, presented 4,185 female professionals, with only one job and who worked up to 45 weekly hours ${ }^{(21)}$.

It is to be noted that $66.8 \%$ of the professionals had employment contracts after passing a public tender, similarly to the National Research of the Nursing Profile, which indicated $65.3 \%$ of the Brazilian professionals working in this service ${ }^{(18)}$. However, the type of contract tends to vary according to the economic scenario of each region, as a study conducted in the Northeast of Brazil found that service provision was the main hiring method $^{(1)}$.

It was also observed that $76.5 \%$ of the professionals presented some sleep change, with $41.8 \%$ being classified as poor sleep, followed by presence of sleep disorders. Such data were similar to the study in the state of Rio Grande do Norte (Brazil), where $60.94 \%$ of the day shift nurses and $85 \%$ of the night shift professionals presented poor sleep quality ${ }^{(22)}$. A research study carried out in an intensive unit in Paraíba (Brazil), obtained $88.24 \%$ of the Nursing team members with sleep changes (classified as poor) ${ }^{(23)}$.

Similarly, a study in hospital units in Iran obtained $77.4 \%$ (418) of the nurses considered as with poor sleep ${ }^{(11)}$. Another study, developed in China with 4,730 nurses working in emergency units, found $65.8 \%$ of the professionals with altered sleep ${ }^{(21)}$. This finding is similar to the study conducted in India, which obtained $83.2 \%$ of the nurses as with poor sleep ${ }^{(10)}$. However, a research study developed in a hospital service in Colombia pointed out only $24.9 \%$ of the professionals with sleep changes, despite sleeping less than 7 hours a day ${ }^{(24)}$.

As for a study carried in hospital from the city of Larestan, in the South of Iran, to assess the prevalence and consequence of sleep changes in nurses, it obtained a mean score of $6.52 \pm 4.23$ in the sleep quality index. And, according to this index, $56 \%$ of the nurses were classified as with poor sleep; therefore, $78.5 \%$ were sleepy, $16.5 \%$ very sleepy and $5 \%$ severely sleepy during labor activities. In addition, the sleep disorders in the professionals who worked in the surgical section were higher than those in the nurses from other hospital units $(\mathrm{p}<0.05)^{(25)}$.

Another study conducted with nurses in the South of Italy has found that women presented worse sleep quality when compared to men, in addition to having less social support at work, which was negatively associated with sleep disorders ${ }^{(26)}$, while a study carried to assess the prevalence and other factors associated with sleep disorder in nurses $(n=422)$ who work in federal government hospitals in Ethiopia, in Adis Abeba, obtained $41.8 \%$ of the participants with sleep changes, especially insomnia, in which work in threeshift rotations, (adjusted OR $=3.1,95 \% \mathrm{CI}: 1.68$ to 5.83 ) was significantly associated with sleep disorder ${ }^{(27)}$.

These differences in the sleep classification using the same research instruments are associated with lifestyle, workload, the physiological stress of each individual(28), gender, age, presence of children, the personality of each professional and the economic conditions of the country ${ }^{(1)}$. In addition to that, the exposure to environmental factors and to work dynamics with high workload and stress is associated with the development of sleep changes ${ }^{(3,5,11,19)}$.

Among the work-associated psychic disorders, CMD develops in different populations, especially in the professions that presented great requirements in the tasks fulfilled ${ }^{(24)}$. This study identified a CMD global prevalence of $36.7 \%$, similar to a study conducted in a public hospital in the state of Bahia (Brazil), which found $35 \%$ of the Nursing professionals with $\mathrm{CMD}^{(6)}$, as well as 
in a research study carried out in a psychiatric hospital with the Nursing team, which obtained $25.7 \%$ as suspected cases(29).

In a study conducted with nursing technicians in a university hospital in the state of Minas Gerais (Brazil), a CMD prevalence of $46.9 \%$ was observed ${ }^{(20)}$. High rates of mental disorders are worrisome in the hospital environment, as they have direct implications on the quality of the care provided to the patients under the Nursing team responsibility ${ }^{(29)}$.

As for the factors associated with sleep changes, the Nursing professionals who were classified with CMD had five times more probabilities of having poor sleep. This fact corroborates a meta-analysis carried out on sleep dissatisfaction and the development of psychic disorders, which found a strong relationship between insomnia and mental changes, including depression, anxiety and suicidal ideation ${ }^{(30)}$.

In a study conducted only with women, the association between CMD and shorter sleep duration was also obtained, pointing out that these changes are the first symptoms detected in psychic disorders. It is highlighted that the women who reported sleeping six hours or less presented 2.66 more chances of CMD when compared to those who slept more than seven hours ${ }^{(31)}$. A research study conducted with Chinese nurses also obtained an association between the presence of anxiety signs (OR $=8.07$, IC 95\%: 2.92-22.33) and poor sleep quality, long latency and insomnia(32).

Likewise, a study also conducted in China with 1,500 nurses in six hospitals from the Shandong province associated the existence of depression symptoms with the presence of sleep disorders and, consequently, with lesser control of the work environment. Nurses are susceptible to the development of work-related mental disorders, thus impairing the quality of the care

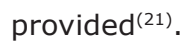

It is also asserted that exposure to stress and poor sleep quality also relate to cognitive failures, such as memory errors, perception, planning, performance of tasks that occur on a daily basis and service provision (33-34). These data are relevant because, in this study, most of the participants were women and reported sleeping 6.5 hours, which can contribute to accidents and risk behaviors. In the context of Nursing, this fact can cause mistakes in the assistance offered, as well as in harms to the patient and the institution.

When the specific components of the Pittsburgh Sleep Quality Index were observed, the domains of sleep quality and sleep disorders presented statistical significance with the type of hospital ( $p$-value $=0.030$ and $<0.001$, respectively) and the time working at the institution ( $p$-value $<0.001$ ).
The first component is assessed by the professionals' perception as to their sleep quality, with $51 \%$ reporting having a good or very good sleep. These data contradict Pittsburgh final classification and corroborate a study developed in Colombia, where $85.7 \%$ of the professionals reported having good and very good sleep quality, although they presented poor sleep quality in the final classification of the instrument(24). It is emphasized that the better assessment can be related to the adaptation to the practice of the service, to working in shifts and to poor quality of sleep as the routine of the activities performed.

As for the type of hospital, in the Brazilian reality, the public institutions face difficult situations, such as insufficient material, and human resources and equipment, lack of beds and overcrowding in the services, which many times lead to professional illnesses ${ }^{(35)}$. In addition to that, despite the improvement in the quality and quantity of the health services, the pattern centered on primary and emergency care overloads the hospital services with high work demands ${ }^{(36)}$. These situations impose limitations to the competence and freedom of the professionals, since they are subjected to stress, suffering and poor working condition, with the objective of performing quality health care ${ }^{(35)}$, at the same time that they have stability as a factor that keeps them in the same employment contract.

In another study conducted in public hospitals in China, presence of poor sleep quality among nurses was obtained, with $68.8 \%$ of those that worked in high-complexity tertiary institutions presenting severe sleep disorders associated with great service demand, a greater number of patients to care of in the night shift and absence of recognition of the work performed(21).

The presence of sleep disorder is assessed by the sum of 9 questions of the instrument that emphasize situations that can disturb sleep, being considered inadequate when exceeding 10 points. In this study, $27.6 \%$ of the professionals were characterized with some sleep disorder, being associated with the public hospital ( $p$-value $<0.001)$ and with longer working time ( $p$-value $<0.001)$. Regarding the hospital component, a study conducted in a regional Colombian institution obtained $10.2 \%$ of the professionals with such disorders, attributed to the environmental characteristics of their home and work ${ }^{(24)}$. Similarly, a research study carried in South Korea with nurses who worked in shifts obtained $50 \%$ of the professionals with sleep disorder, with $28 \%$ of them presenting severe sleep changes, fatigue and depression associated with the work in hospital units ${ }^{(36)}$. 
A study conducted in Iran obtained a lower prevalence of sleep disorders, in which only $7.4 \%$ of the professionals presented severe insomnia, especially in night-shift workers ${ }^{(23)}$. A research study conducted in Sweden with newly graduated nurses obtained presence of sleep changes related to the concerns and persistent thoughts about work, in addition to a high load of activities ${ }^{(28)}$.

An integrative literature review study on the current knowledge and attitudes in relation to the impact of sleep disorders on health and on the cognitive functions among the Nursing team members in Europe showed that $30 \%$ to $70 \%$ of the nurses sleep less than six hours before the shift. Regarding the cognitive effects of sleep deprivation, it was observed that it impairs the performance of tasks that require prolonged and intensive attention, which increases the number of errors when serving the patient ${ }^{(37)}$.

It is also highlighted that the night shift, both with fixed and alternate working hours, is harmful to the professionals' health, as it alters the productions of melatonin(38), reduces work safety, productivity, performance and quality of life ${ }^{(39)}$, being related to gastrointestinal problems, pain in the back and neck, fatigue, depression, tiredness, stress, cardiovascular diseases and early mortality ${ }^{(4,31)}$. In addition, the 12 hour working day followed by 36 hours of rest makes it easier for the employee to have a second job ${ }^{(23)}$. Having more than one employment contract generates extensive working days, with partial or nonexistent rest, which favors poor sleep quality.

In addition to that, with longer time working at the hospital institution, the development of skillful care is observed; however, with the professional experience, there is longer time of exposure to occupational stressors, which facilitates the development of sleep disorders ${ }^{(22,24)}$ and can wrongly contribute to reducing the perception of the need for protection against accidents and the understanding about one's own health status $^{(35)}$.

Sleep latency is assessed by the time needed to fall asleep, from the wakefulness stage to total sleep and, in this study, statistical significance was observed with having a job ( $p$-value<0.001) and longer working time ( $p$-value $=0.001$ ). In addition to that, the mean time to fall asleep referred was 31.9 minutes, with a mean of 6.5 sleep hours. In a research study conducted in São Paulo (Brazil), it was found that $35.29 \%$ of the professionals reported needing more than 30 minutes to fall asleep (23), as well as in study carried out in China, which obtained a higher latency among the professionals $^{(40)}$ and a research study conducted in
Colombia, in which $34 \%$ of the professionals needed more than 28 minutes to fall asleep ${ }^{(24)}$.

It is also known that sleep is influenced by hemodynamic conditions, temperature, environmental sounds, social activities and exposure to light. The latter has an important effect on the initiation and maintenance of this process, since artificial light alters the circadian and sleep-wake cycles ${ }^{(41)}$.

Furthermore, a study shows that there is large exposure to artificial light in the general population, with a constant increase in the last years, which, along with the environmental working factors, influences sleep quality $^{(31)}$. It is suggested that the professionals with a job expose themselves more to artificial light during their leisure time, which, together with work exposure, contribute to difficulty in falling asleep.

In this study, statistical significance between the working shift and sleep duration was observed ( $p$-value<0.001), in which the period of the day demonstrated higher mean points, suggesting that these professionals present fewer resting hours. However, national and international surveys obtained sleep disorders with worse quality in the night period $^{(1,2,10,26,28,33,35,42)}$.

It is also pointed out that the anxiety and stress levels have an effect on the sleep assessment tool, as well as on the quality and duration of the physiological process. In this way, professionals of the day shift present more accentuated work routines, which contributes to more frequent awakenings at night, insomnia and less sleep time ${ }^{(35)}$.

The usual effectiveness of sleep is assessed in the question on how many hours were slept in relation to the time in bed, with white skin color ( $p$-value $=0.010$ ), two or more jobs ( $p$-value $=0.040$ ) and more than 40 working hours ( $p$-value $=0.030$ ) presenting higher mean scores in this study.

It is also pertinent to state that, despite the economic growth of the Nursing profession, the submission to long working hours and the duplicity of jobs are similar to the medical profession, which intensifies the risk of illnesses, dissatisfaction with sleep and insomnia(43). A study carried out in China with physicians and nurses found that the workers presented very different sociodemographic and occupational characteristics and that the nurses had significantly greater mental health problems and sleep changes than the other workers ${ }^{(42)}$.

It is also contemplated that, in case of more than one employment contract and extensive workloads, the time devoted to sleep becomes scarce, the secretion of cortisol and the central temperature of the organism increase, with a reduction of melatonin and a consequent 
decrease of sleep efficiency and its duration ${ }^{(44-45)}$. A study developed in hospitals from Ontario, Canada, highlights that the extensive working days and the increasing number of overtime hours in Nursing exert an influence on the well-being of the patient, on the finance of the health institutions, on satisfaction and on the nurses' health. This fact was justified by financial gain, career development, assistance offered to the colleagues and to maintain care continuity ${ }^{(44)}$.

Regarding the long working days, they were also observed in a study developed with nurses from Thailand, in which $79.34 \%$ of the participants reported an 8-hour workload, although they worked a mean of 58.82 hours during the week. In addition, $32.81 \%$ of the professionals indicated low job satisfaction and only $54.4 \%$ reported having adequate sleep ${ }^{(45)}$. As for the significant difference between skin color and the specific component, no studies similar to the result obtained were found in the literature.

Regarding the use of sleep medications, it was reported by $33.7 \%$ of the professionals, with varying frequency during the week. The specific component showed a significant difference with the public hospital ( $p$-value $=0.030)$, females ( $p$-value $=0.040)$, one job ( $p$-value $=0.010)$ and longer time in the institution ( $p$-value $=<0.001$ ), corroborating a research study carried out with the Nursing team from a public hospital, in which $51 \%$ of the participants used sleep medications ${ }^{(46)}$. As for a study carried out in Colombia, it was found that only $4.1 \%$ of the professionals used sleep medications ${ }^{(24)}$, similarly to another research study with nurses from Ethiopia, in which $24.6 \%$ of the participants made use of some medication to improve sleep quality (27).

It is contemplated that the professionals justify taking a medication due to stress, excessive workload, poor working conditions and poor sleep quality. In addition, self-medication is considered a phenomenon that occurs more frequently among women, with high schooling and with facilitated access to the drugs ${ }^{(27,46)}$, a profile similar to the Brazilian.

As for the daytime dysfunction component, assessed by the question on remaining awake in routine tasks and excited to carry out the activities, a statistical significance with the hospital variable $(p$-value $=0.010$ ) was observed, with a higher value for the public institution, suggesting greater sleepiness during the day in the professionals from the public service and poor subjective sleep quality.

Regarding the limitations of this research, the cross-sectional design stands out, which prevents data generalization and the monitoring of the changes developed by the professionals, as well as the non- investigation of the individuals away from work. In addition to that, it was not the objective of the study to assess the rest conditions and social support in the work environment, variables that can influence the development of mental disorders and sleep changes. It is also noted that the sample was mostly composed of nursing technicians, as well that the instruments are self-applied and were made available to the participants for completion, with return scheduled at a later date. Such criteria can contribute to bias, perhaps affected by the interest and attitudes of the research participants.

The prevalence of sleep changes in the Nursing team corroborates national and international research studies, demonstrating that the lack of adequate sleep can contribute to professional illnesses and to worse Nursing care quality. Thus, it is believed that the data presented may collaborate to the understanding of the work dynamics of the Nursing professionals, lead to management changes, in order to monitor health changes and favor the elaboration of promotion and prevention programs for this population group.

However, the health policies, implemented by the managers, must propose actions that aim at to protect and to promote of the workers' mental and physical health, reducing the adverse events in care, high rotation in the services, the increase in the hospital costs and dismissals associated with professional illnesses ${ }^{(3,5,24)}$.

\section{Conclusion}

A priori, it is contemplated that poor sleep quality and sleep disorder were prevalent in the sample and, when the sociodemographic variables were observed, the presence of common mental disorder showed to be a factor associated with sleep changes. In addition to that, among the sociodemographic and occupational data, the public hospital, being female, white skin color, having a job, working more than forty hours a week, longer working time in the institution, and the night shift showed an association with the assessment of sleep quality.

\section{Acknowledgments}

In gratitude to all the Nursing professionals, of the different hospitals that participated in this research.

\section{References}

1. Machado LSF, Rodrigues EP, Oliveira LMM, Laudano RCS, Nascimento Sobrinho CL. Health problems reported by nursing workers in a public hospital of Bahia. Rev 
Bras Enferm. 2015;67(5):684-91. doi: http://dx.doi. org/10.1590/0034-7167.2014670503

2. Silveira M, Camponogara S, Beck CLC. Scientific production about night shift work in nursing: a review of literature. J Res Fundam Care. 2016;8(1):3679-90. doi: 10.9789/2175-5361. 2016.v8i1.3679-3690.

3. Dall'Ora C, Ball J, Reinius M, Griffiths P. Burnout in nursing: a theoretical review. Hum Resour Health. 2020;18(41). doi: https://doi.org/10.1186/s12960-02000469-9

4. Argent AC, Benbenishty J, Flaatten H. Chronotypes, night shifts and intensive care. Intensive Care Med. 2015;41(4):698-700. doi: http://dx.doi.org/10.1007/ s00134-015-3711-7

5. Ki J, Ryu J, Baek J, Huu I, Choi-Kwon, S. Association between Health Problems and Turnover Intention in Shift Work Nurses: Health Problem Clustering. Int J Environ Res Public Health. 2020;17(4532). doi: 10.3390/ ijerph17124532.

6. Rodrigues EP, Rodrigues US, Oliveira LLM, Laudano RCS, Nascimento Sobrinho CL. Prevalence of common mental disorders in nursing workers at a hospital of Bahia. Rev Bras Enferm. 2014;67(2):296-301. doi: http://dx.doi. org/10.5935/0034-7167.20140040

7. Vidotti V, Ribeiro RP, Galdino MJQ, Martins JT. Burnout Syndrome and shift work among the nursing staff ${ }^{1}$. Rev. Latino-Am. Enfermagem. 2018;26:e3022. doi: http:// dx.doi.org/10.1590/1518-8345.2550.3022

8. Wang L, Wang X, Liu S, Wang B. Analysis and strategy research on quality of nursing work life. Medicine. 2020;99(16):e19172. doi: 10.1097/ MD.000000000019172.

9. Guerra PC, Oliveira NF, Terreri MTSLRA, Len CA. Sleep, quality of life and mood of nursing professionals of pediatric intensive care units. Rev Esc Enferm USP. 2016;50(2):277-83. doi: http://dx.doi.org/10.1590/ S0080-623420160000200015

10. Roodbandi AJ, Choobineh A, Daneshvar S. Relationship between circadian rhythm amplitude and stability with sleep quality and sleepiness among shift nurses and health care. International Int J Occup Saf Ergon. 2015;21(3):3127. doi: $10.1080 / 10803548.2015 .1081770$.

11. Khatony A, Zakiei A, Khazaie H, Rezaei MJ. A study of sleep quality among nurses and its correlation with cognitive factors. Nurs Admin Quarterly. 2020;44(1):110. doi: 10.1097/NAQ.0000000000000397.

12. Sena AG, Figueiredo ML, Mota EC, Costa FM, Prado PF, Lima CA. Life Quality: The Night Shift Work Challenge To Nursing Team. J Res Fundam Care. 2018;10(3):832-9. doi: http://dx.doi.org/10.9789/21755361.2018.v10i3.832-839

13. Santos SVM, Macedo FRM, Silva LM, Resck ZMR, Nogueira DA, Terra FS. Work accidents and self-esteem of nursing professional in hospital settings. Rev. LatinoAm. Enfermagem. 2017;25:e2872. doi: http://dx.doi. org/10.1590/1518-8345.1632.2872

14. Davidson JE, Proudfoot J, Lee K, Tarterian G, Zissok S. A Longitudinal Analysis of Nurse Suicide in the United States (2005-2016) With Recommendations for Action. Worldviews Evid Based Nurs. [Internet]. 2020 [cited Mar 23, 2020];17(1):6-15. Available from: https://sigmapubs. onlinelibrary.wiley.com/doi/epdf/10.1111/wvn.12419

15. Gonçalves DM, Stein AT, Kapczinski F. Performance of the Self-Reporting Questionnaire as a psychiatric screening questionnaire: a comparative study with Structured Clinical Interview for DSM-IV-TR. Cad. Saúde Pública. 2008;24(2):380-90. doi: http://dx.doi.org/10.1590/ S0102-311X2008000200017

16. Bertolazi AN, Fagondes SC, Hoff LS, Dartora EG, Miozzo ICS, Barba EMF, et al. Validation of the Brazilian Portuguese version of Pittsburgh Sleep Quality Index. Sleep Med. 2011;12(1):70-5. doi: https://doi. org/10.1016/j.sleep.2010.04.020

17. Fernandes DM, Marcolan JF. Work and depression symptoms in Family Health Strategy nurses. Rev Eletrônica Saúde Mental Álcool Drogas. 2017;13(1):37-44 doi: 10.11606/issn.1806-6976.v13i1p37-44.

18. Conselho Federal De Enfermagem. Pesquisa Perfil da Enfermagem no Brasil. [Homepage]. [Acesso 20 dez 2018]. Available from: http://www.cofen.gov.br/ perfilenfermagem/index.html

19. Santana LC, Ferreira LA, Santana LPM. Occupational stress in nursing professionals of a university hospital. Rev Bras Enferm. 2020;73(2):e20180997. doi: http:// dx.doi.org/10.1590/0034-7167-2018-0997

20. Santos FF, Brito MFSF, Pinho L, Cunha FO, RodriguesNeto JF, Fonseca ADG, et al. Common mental disorders in nursing technicians of a university hospital. Rev Bras Enferm. 2020;73(1):e20180513. doi: http://dx.doi. org/10.1590/0034-7167-2018-0513

21. Dong H, Zhang Q, Zhu C, Lv Q. Sleep quality of nurses in the emergency department of public hospitals in China and its influencing factors: a cross-sectional study. Health Qual Life Outcomes. 2020;18(116). doi: doi.org/10.1186/ s12955-020-01374-4.

22. Silva KKM, Martino MMF, Viana MCO, Bezerra CMB, Miranda FAN. Relationship between work shifts and quality of sleep of nurses: a descriptive study. Online Braz J Nurs. [Internet]. 2017 [cited Mar 23, 2020];16(1):57-63. Available from: http://www.objnursing.uff.br/index.php/ nursing/article/view/5577

23. Santos TCMM, Faria AL, Feitosa MS, Coimbra GT, Ferreira LC, Martino MMF. Quality and sleep disturbances of the nursing staff of a therapy unit. Rev Enferm UFPE Online. 2014;8(5):1110-6. doi: 10.5205/reuol.586350531-1-ED.0805201402. 
24. Moreno JPS, Ariza DAM. Sleep Quality of Nurses Staff. Rev Cienc Salud. 2018;16 (Spec Iss):75-86. doi: http://dx.doi.org/10.12804/revistas.urosario.edu.co/ revsalud/a.6846

25. Bazrafshan MR, Rahimpoor R, Moravveji F, Soleymaninejad N, Kavi E, Sookhak F, et al. Prevalence and Effects of Sleep Disorders Among Shift Work Nurses. Jundishapur J Chronic Dis Care. 2019;8(1):e81185. doi: 10.5812/jjcdc.81185.

26. D'Ettorre G, Pellicani V, Caroli A, Greco M. Shift work sleep disorder and job stress in shift nurses: implications for preventive interventions. Med Lav. 2020;111(3):195202. doi: 10.23749/mdl.v111i3.9197.

27. Haile KK, Asnakew S, Waja T, Bogale Kerbih HB. Shift work sleep disorders and associated factors among nurses at federal government hospitals in Ethiopia: a cross-sectional study. BMJ Open. 2019;9(8):e029802. doi: 10.1136/bmjopen-2019-029802.

28. Epstein $M$, Söderström $M$, Jirwe $M$, Tucker $P$, Dahlgren A. Sleep and fatigue in newly graduated nurses Experiences and strategies for handling shiftwork. J Clin Nurs. 2020;29:184-194. doi: 10.1111/jocn.15076.

29. Silva JSX, Silva RM, Cangussu DDD, MoraesFilho IM, Perez MA, Proença MFR. Qualidade do sono dos profissionais de enfermagem do serviço móvel de atendimento de urgência. REVISA. 2019;8(3):264-72 doi: https://doi.org/10.36239/revisa.v8.n3.p264a272

30. Wilkeman JW. Insomnia Disorder. N Engl J Med. 2015;373:1437-44. doi: 10.1056/NEJMcp1412740.

31. Sericato C, Azevedo RCS, Barros MBA. Common mental disorders in adult women: identifying the most vulnerable segments. Ciênc Saúde Coletiva. 2018;23(8):2543-54. doi: http://dx.doi.org/10.1590/1413-81232018238.13652016 32. Zhi-Hao T, Jing-Wen E, Na Z. Sleep quality and mood symptoms in conscripted frontline nurse in Wuhan, China during COVID-19 outbreak. A cross-sectional study. Medicine. 2020;99(26):e20769. doi: 10.1097/ MD.0000000000020769

33. Imamura $K$, Tran $\Pi T$, Nguyen $H T$, Kuribayashi $K$, Sakuraya A, Nguyen AQ, et al. Effects of two types of smartphone-based stress management programmes on depressive and anxiety symptoms among hospital nurses in Vietnam: a protocol for three-arm randomised controlled trial. BMJ Open. 2019;9(4):e025138. doi: http://dx.doi.org/10.1136/bmjopen-2018-025138 34. Rosado IVM, Russo GHA, Maia EMC. Generating health elicits illness? The contradictions of work performed in emergency care units of public hospitals. Ciênc Saúde Coletiva. 2015;20(10):3021-32. doi: 10.1590/1413812320152010.13202014.

35. O'Dwyer G, Konder MT, Machado CV, Alves CP, Alves RP. The current scenario of emergency care policies in
Brazil. Health Services Research. 2013;13(70):2-10. doi: http://www.biomedcentral.com/1472-6963/13/70

36. Stanojević C, Simić S, Milutinović D. Health effects of sleep deprivation on nurses working shifts. Med Pregl. 2016;(5-6):183-8. doi: 10.2298/MPNS1606183S.

37. Jensen HI, Markvart J, Hoslt R, Thomsen TD, Larsen JW, Eg DM, et al. Shift work and quality of sleep: effect of working in designed dynamic light. Int Arch Occup Environ Health. 2016;89:49-61. doi: 10.1007/s00420015-1051-0.

38. Chinoy ED, Harris MP, Kim JJ, Wang W, Duffy JF. Scheduled evening sleep and enhanced lighting improve adaptation to night shift work in older adults. Occup Environ Med. 2016;73:869-76. doi: 10.1136/ oemed-2016-103712.

39. Jensen HA, Larsen JW, Thomsen TD. The impact of shift work on intensive care nurses' lives outside work: A cross-sectional study. Clin Nurs. 2017;27:e703-9. doi: https://doi.org/10.1111/jocn.14197

40. Mulhall MD, Sletten TL, Magee M, Stone JE, Ganesan $S$, Collins $A$, et al. Sleepiness and driving events in shift workers: the impact of circadian and homeostatic factors. Sleep. 2019;42(6):6-11. doi: https://doi.org/10.1093/ sleep/zsz074

41. Sousa KHJF, Soares ECF, Moraes KG, Batista KC, Gonçalves TS, Zeitoune RCG. Factors associated with the profile of the nursing team of a psychiatric hospital and its implications for occupational health. Rev Min Enferm. 2018;22:e-1104. doi: 0.5935/1415-2762.20180032.

42. Tong $Y$, Jiang ZK, Zhang YX, Jia JL, Lu W, Tang $\mathrm{HJ}$, et al. Analyzing the mental health status and its impact factors among female nurses in China. Medscape. 2018;36(2):115-8. doi: $10.3760 / \mathrm{cma}$.j.is sn.1001-9391.2018.02.009.

43. Díaz-Ramiro EM, Rubio-Valdehita S, López-Núñez MI, Aparicio-García ME. Sleep habits as predictors of psychological health in healthcare professionals. Ann Psychol. 2020;36(2). doi: https://doi.org/10.6018/ analesps. 350301

44. Lobo VM, Ploeg J, Fisher A, Peachey G, Akhtar-Danesh N. Critical Care Nurses' Reasons for Working or Not Working Overtime. Critical Care Nurse. 2018;38(6):4757. doi: https://doi.org/10.4037/ccn2018616

45. Kunaviktikul W, Wichaikhum O, Nantsupawat $A$, Nantsupawat R, Chontawan R, Klunklin A, et al. Nurses' extended work hours: Patient, nurse and organizational outcomes. Int Nurs Rev. 2015;62(3):386-93. doi: 10.1111/inr.12195.

46. Oliveira FA, Teixeira ER. Conception about selfmedication use by the nursing staff in oncology intensive care. Rev Enferm UFPE On Line. 2016;10(1):24-31. doi: 10.5205/reuol.8423-73529-1-RV1001201604. 


\section{Authors' contribution:}

Study concept and design: Jolana Cristina Cavalheiri, Claudicéia Risso Pascotto, Nelsi Salete Tonini, Ana Paula Vieira, Lirane Elize Defante Ferreto, Franciele Ani Caovilla Follador. Obtaining data: Jolana Cristina Cavalheiri, Claudicéia Risso Pascotto, Ana Paula Vieira, Franciele Ani Caovilla Follador. Data analysis and interpretation: Jolana Cristina Cavalheiri, Claudicéia Risso Pascotto, Nelsi Salete Tonini, Ana Paula Vieira, Lirane Elize Defante Ferreto, Franciele Ani Caovilla Follador. Statistical analysis: Jolana Cristina Cavalheiri, Lirane Elize Defante Ferreto. Drafting the manuscript: Jolana Cristina Cavalheiri, Nelsi Salete Tonini, Lirane Elize Defante Ferreto, Franciele Ani Caovilla Follador. Critical review of the manuscript as to its relevant intellectual content: Claudicéia Risso Pascotto, Nelsi Salete Tonini, Ana Paula Vieira, Lirane Elize Defante Ferreto, Franciele Ani Caovilla Follador.

All authors approved the final version of the text.

Conflict of interest: the authors have declared that there is no conflict of interest. Creative Commons (CC BY).

This license lets others distribute, remix, tweak, and build upon your work, even commercially, as long as they credit you for the original creation. This is the most accommodating of licenses offered. Recommended for maximum dissemination and use of licensed materials. 